EDITOR'S

\title{
Measuring quality in the therapeutic relationship-Part 2: subjective approaches
}

\author{
Trisha Greenhalgh, ${ }^{1}$ Iona Heath ${ }^{2}$
}

${ }^{1}$ Healthcare Innovation and Policy Unit, Centre for Health Sciences, Barts and The London School of Medicine and Dentistry, London, UK ${ }^{2}$ Royal College of General Practitioners, London, UK

\section{Correspondence to}

Professor Trisha Greenhalgh, Professor of Primary Health Care and Director, Healthcare Innovation and Policy Unit, Centre for Health Sciences, Barts and The London School of Medicine and Dentistry, Abernethy Building, 2 Newark Street, London E1 2AT, UK; p.greenhalgh@qmul.ac.uk

Accepted 18 July 2010

\section{ABSTRACT}

Background The therapeutic relationship is complex and incompletely captured in objective metrics.

Aim To review the different concepts, theoretical models and empirical approaches which researchers have used to capture in qualitative terms what is special about the relationship between practitioner and patient.

Method Drawing on the principles of meta-narrative systematic review (but without seeking an exhaustive inventory of every paper ever published), we considered different research traditions in terms of their respective philosophical assumptions, methodological strengths and limitations and empirical findings. We applied published quality criteria from each tradition to papers within that tradition.

Results Four research approaches were oriented to producing subjective interpretations of quality in the therapeutic relationship. These had emerged in different research traditions: psychodynamic (eg, the Balint method, whose roots are in psychoanalysis); narrative (literary theory, moral philosophy); critical consultation analysis (critical sociology) and socio-technical analysis (actor-network theory). Each emphasised a different dimension of relationship quality.

Conclusion Subjective (interpretive) approaches do not lend themselves readily to metrics or scales, but they can inform a structured list of questions to prompt practitioner reflection. A combination of objective metrics and reflective practice has considerable quality improvement potential.

\section{INTRODUCTION}

This is the second in a pair of papers which considers how and to what extent the quality of the therapeutic relationship between practitioner and patient can be measured. A previous paper considered objective approaches such as survey instruments and interaction analysis tools, oriented to producing 'facts' (scores and categories). ${ }^{1}$ This paper considers subjective approaches oriented to producing interpretations and other qualitative insights.

In this review, we asked three questions: First, how have different researchers and scholars sought to measure or understand the therapeutic relationship? Second, what are the strengths and limitations of the various metrics and measures on offer? Third, what are the practical implications for quality improvement? This paper and its companion are based on a longer monograph published by the Kings Fund, London. ${ }^{2}$

\section{METHOD}

In seeking to map the different ways in which the therapeutic relationship has been conceptualised, theorised and empirically studied, we used an adaptation of meta-narrative review, based on Kuhn's notion of the scientific paradigm (a coherent body of work that shares a common set of concepts, theories, methods and instruments). ${ }^{3}{ }^{4}$ It is particularly suited to exploring tensions and paradoxes between different research approaches and making sense of 'conflicting' findings. ${ }^{5}$ Our search strategy has been described previously. ${ }^{1}$ In appraising primary studies, we took our quality criteria from seminal sources in the tradition we were studying. For example, when appraising papers written from a psychodynamic perspective, we prioritised studies that scored well on criteria such as interpretive scholarship, authenticity and reflexivity. ${ }^{6}$

\section{MAIN FINDINGS \\ 'Measuring' the therapeutic relationship: research approaches}

Table 1 summarises the characteristics of four subjective research traditions identified in this review which have contributed to the knowledge base on the therapeutic relationship:

1. Psychodynamic analysis (especially the Balint method, whose roots are in psychoanalysis), which uses reflection and discussion to consider the unconscious and irrational forces underpinning the intersubjective relationship between patient and practitioner

2. Narrative analysis (whose roots are in literary theory and moral philosophy), which views patient and practitioner as teller and listener (or perhaps co-constructors) of an illness narrative.

3. Critical consultation analysis (whose roots are in sociology), which seeks to identify and expose the hidden tensions and socially determined power relations in the therapeutic relationship.

4. Socio-technical analysis (whose roots are in actor-network theory), which considers the patient and practitioner as part of a wider 'care network' of people and technologies.

We consider these approaches in turn below.

The Balint approach: the therapeutic relationship as a reflection of unconscious and irrational forces Balint was a Hungarian psychoanalyst whose approach was derived from the work of Freud. ${ }^{7}{ }^{14}$ Psychoanalysis takes as its starting point that unconscious and often irrational motives drive much of our behaviour. In applying psychoanalytic principles to the relationship between patient and family practitioner, Balint made three critical observations:

- General practice includes a high prevalence of neurotic illness-that is, with symptoms that can be traced back to desires or fears repressed into the unconscious. 
Table 1 Different subjective research approaches to the study of the therapeutic relationship (see companion paper for objective approaches) ${ }^{1}$

\begin{tabular}{|c|c|c|c|c|}
\hline Approach & Discipline & $\begin{array}{l}\text { General format of research } \\
\text { question }\end{array}$ & Preferred study design & $\begin{array}{l}\text { Quality defined in terms of } \\
\text { (=> potential for 'metrics') }\end{array}$ \\
\hline $\begin{array}{l}\text { 1. Psycho-dynamic } \\
\text { analysis (eg, the } \\
\text { Balint method) }\end{array}$ & Psycho-analysis & $\begin{array}{l}\text { What unconscious and irrational } \\
\text { forces are at work in the consultation, } \\
\text { and how can these be used } \\
\text { therapeutically? }\end{array}$ & $\begin{array}{l}\text { Reflexive discussion in which } \\
\text { unconscious/irrational motives of } \\
\text { doctor and patient are explored } \\
\text { (eg, in a Balint group) }\end{array}$ & $\begin{array}{l}\text { Attention to the hidden agenda: } \\
\text { To what extent does the clinician } \\
\text { connect emotionally with the patient, } \\
\text { show unconditional positive regard } \\
\text { and allow the 'real' reason for the } \\
\text { consultation (perhaps a neurotic } \\
\text { illness) to be revealed and dealt } \\
\text { with }^{7}{ }^{8} \text { ? }\end{array}$ \\
\hline 2. Narrative analysis & $\begin{array}{l}\text { Literary theory, } \\
\text { moral philosophy }\end{array}$ & $\begin{array}{l}\text { How does the teller-listener } \\
\text { relationship influence the narration } \\
\text { and enactment of the illness narrative } \\
\text { and how might 'active listening' be } \\
\text { supported? }\end{array}$ & $\begin{array}{l}\text { Close reading of texts (eg, patients' } \\
\text { stories) }\end{array}$ & $\begin{array}{l}\text { Narrative competence: To what } \\
\text { extent does the co-constructed illness } \\
\text { story (a)] place the patient as } \\
\text { narrator/subject and the practitioner } \\
\text { as active listener/witness, (b) achieve } \\
\text { coherence and moral order and (c) } \\
\text { reflect mutual trust and obligation? }^{9} 10\end{array}$ \\
\hline $\begin{array}{l}\text { 3. Critical consultation } \\
\text { analysis }\end{array}$ & Socio-linguistics & $\begin{array}{l}\text { What external social forces shape, } \\
\text { enable and constrain the therapeutic } \\
\text { relationship? What is the nature of } \\
\text { trust in this relationship? }\end{array}$ & $\begin{array}{l}\text { In-depth qualitative designs, for } \\
\text { example, ethnography, conversation } \\
\text { analysis, narrative interview }\end{array}$ & $\begin{array}{l}\text { Power dynamics: system/lifeworld: } \\
\text { To what extent is interaction in the } \\
\text { consultation communicative and } \\
\text { based on voluntary trust? To what } \\
\text { extent is the discourse of the patient's } \\
\text { lifeworld given space? } \text { ? }^{11}\end{array}$ \\
\hline $\begin{array}{l}\text { 4. Socio-technical } \\
\text { analysis }\end{array}$ & $\begin{array}{l}\text { Philosophy } \\
\text { (actor-network theory) }\end{array}$ & $\begin{array}{l}\text { How is the therapeutic relationship } \\
\text { situated within the wider care } \\
\text { network of people and technologies, } \\
\text { and what emerges from it? }\end{array}$ & $\begin{array}{l}\text { Ethnography (detailed observation of } \\
\text { talk and action in a naturalistic } \\
\text { setting) }\end{array}$ & $\begin{array}{l}\text { Underlying logic: To what extent is } \\
\text { the therapeutic relationship } \\
\text { underpinned by the logic of care } \\
\text { (continuous, adaptive and affective) } \\
\text { as opposed to the logic of choice } \\
\text { (episodic, decision focused and } \\
\text { objective)? }^{13}\end{array}$ \\
\hline
\end{tabular}

- Trivial and 'inexplicable' complaints are the main vehicle through which this type of illness presents to the practitioner.

- The key to healing in neurotic illness is the persona of the practitioner-that is, such patients need, more than anything else, a dose of what Balint memorably called 'the doctor as the drug'?

Balint encouraged general practitioners to reflect in groups on clinical cases in order to reveal the hidden meaning of the emotions they had felt and how they and the patient had behaved. Balint considered objectivity to be an over-rated virtue, inherently impossible to achieve. Rather, he argued, the doctor's subjectivity (and particularly, reflexive attention to his or her own emotional responses in the consultation) is the key to both making the diagnosis and defining an appropriate treatment. The clinical interaction in general practice, Balint believed, is a complex dialogue held over time and in an atmosphere of trust, which will reveal insights into the nature of neurotic illness and offer scope for its cure.

Balint's influential work built on the earlier work of Carl Rogers, who challenged the widespread assumption of the day that the therapist's behaviour was the essential element in healing. ${ }^{8}$ Rogers argued that the relationship conditions offered by the therapist (empathy, congruence and unconditional positive regard) were in and of themselves therapeutic. This suggestion has since been confirmed empirically and underpins a large body of work on psychotherapeutic approaches to the clinical encounter. ${ }^{15} 16$ The evidence summarised in these reviews has consistently shown that 'objective' measures of the quality of the relationship are less good predictors of outcome than subjective ones such as mutual warmth.

Narrative approaches: the therapeutic relationship as co-construction of a story by teller and listener

All stories have four things in common: characters, setting, trouble and plot. ${ }^{17}$ In the illness narrative, trouble is disease, disability, disfigurement and so on-plus the accompanying loss of social status and independence. ${ }^{18}$ Coping with illness and minimising its impact requires perseverance and forbearance. Every ill person faces different day-to-day challenges, a different family context, different constraints of work or neighbourhood and different moral choices. Constructing an illness narrative in the therapeutic encounter allows us to make sense of our trouble and develop plans for coping with it in the context of our lives. ${ }^{9}$

Bakhtin argued that all stories are a dialogue. ${ }^{19}$ The role of the listener is not merely to absorb a story passively, but to provide an engaged and critical audience for it. ${ }^{10}$ Drawing on Bakhtin, Frank takes issue with conventional biomedical perspectives which encourage doctors to use listening as a 'tool' for extracting information that can contribute to a problem solving sequence. In such an approach, "the [patient] remains the object of the professional's privileged subjectivity: there is no relationship in the sense of reciprocated feeling for one another'. ${ }^{10}$

The clinician, suggests Frank, provides the subjective 'otherness' for an interactional narrative in which the patient will construct, and make sense of, his or her illness narrative. The accumulation of (often brief and disjointed) clinician-patient encounters over time constitutes above all else 'just listening' to an unfolding narrative of restitution (the illness gets better), tragedy (the illness gets worse) or quest (the illness gets worse but the sufferer finds fulfillment in facing and coping with it). ${ }^{20}$

The clinical encounter has a significant ethical dimension which emerges from the particularities of the story. This stance draws on a number of philosophers (eg, Buber, Heidegger) broadly classified as existentialists, who emphasised not merely the ability to connect with the patient but the need to be fully present and open to being changed by the patient's unfolding story. $^{21} 22$ What Buber referred to as the 'I-thou' relationship (intersubjective, mutually constitutive, ethical, fundamentally different from any 'I-it' relationship) has close parallels to what Rita Charon calls narrative competence (the ability to acknowledge, absorb, interpret and act on the stories and plights 
of others ${ }^{9}$ ). This is, perhaps, the essence of what will be missed if the therapeutic relationship is assessed solely in terms of the objectively measurable. ${ }^{23}$

\section{Critical consultation analysis: the therapeutic relationship as an unequal power struggle}

Medical sociologists have studied the consultation from the perspective of socio-linguistics, in which researchers ask why particular utterances were made in particular ways at particular times. This critical analysis extends beyond the consultation and considers the social context and power relationships within which talk gains a particular, contextual meaning. ${ }^{24}$

Habermas distinguished between the discourses of 'system' (economy and state) and 'lifeworld' (family and household). ${ }^{25}$ The 'micro' of interpersonal relationships links with the 'macro' of society and state such that any particular doctor-patient encounter is a product of the roles of 'doctor' and 'patient' in wider society and is influenced by wider political and economic forces. $^{26} 27$

Using a socio-linguistic technique called conversation anal$y \operatorname{sis}^{28}$ to analyse consultation transcripts, Mishler demonstrated that the patient's lifeworld is colonised by the 'voice of medicine' (an example of encroachment by the state into the personal world). ${ }^{29}$ Subsequent empirical studies have confirmed and refined Mishler's original model. ${ }^{30}{ }^{31}$ For example, Barry et al revealed the subtle ways in which the doctor imposes the 'voice of medicine' on what is said:

\begin{abstract}
...the [apparently] unremarkable interview, while appearing coherent and fluent on the surface, fragments meaning by means of frequent interruption, lack of acknowledgement of responses and shifts of topic with no reason given. The doctor is in control as both first and last speaker in each exchange. Only the doctor is involved in developing the topic of talk, by asking a series of seemingly (to the patient) disconnected questions. ... [T] he cost is a loss of context in terms of how the problem developed (the history and course) and the effects on the patient's life. ${ }^{30}$
\end{abstract}

A key theme in this critical literature is trust-especially 'hegemonic trust' - when the system has colonised the individual's lifeworld so effectively that he or she ceases to question an oppressive situation (eg, when disempowered patients believe that the doctor is very important and should never be challenged or interrupted). ${ }^{32}$

\section{Socio-technical approaches: the therapeutic relationship as part of a wider care network}

An important question about the therapeutic relationship is 'what is its underpinning logic?' Philosopher Annemarie Mol has written a seminal book called The Logic of Care, based on a detailed ethnographic study of patient-doctor and patientnurse encounters in diabetes. ${ }^{13}$ She argues that healthcare is often driven by an underlying logic of choice-especially informing and supporting the decisions and choices of an 'empowered' patient. ${ }^{33}$

Important though choice is, Mol argues that it is secondary to the core business of clinical care, especially in chronic illness. The logic of care differs in important respects from the logic of choice, not least that it is continuous rather than episodic, affective rather than objective, and sees the clinician and patient as on the same 'side' rather than polarised into (say) 'patient centred' or 'doctor/nurse centred'. Whereas in the logic of choice, the focus is on particular decisions made by a rational patient at particular time points, the logic of care emphasises the ongoing, never-ending work from both patient and clinician that goes into the complex task of living with an illness. It also accommodates the irrational, inconsistent and even selfdestructive impulses that drive all of us sometimes when we are sick or confused, and lets the patient shift between active and passive as appropriate to their illness and needs.

Mol writes (broadly) from the perspective of actor-network theory-an imaginative philosophical approach which sees people and technologies as linked in complex, ever-changing and inherently unstable networks. ${ }^{34}$ This conceptual lens, which has some affinity with critical consultation analysis described above (especially, the focus on questioning taken-for-granted assumptions about social relationships), allows the analysis of quality in the therapeutic relationship to move into a more contemporary era-for example, by placing less emphasis on the doctor-patient relationship as the sole focus of care and more on how the wider network of doctors, nurses, receptionists, lay carers and the patient themselves can work flexibly to identify and meet a changing set of needs.

\section{DISCUSSION}

The subjective evidence reviewed above consistently demonstrates that the therapeutic relationship requires high-quality interpersonal engagement (being 'fully present', showing 'narrative competence', linking with the 'lifeworld' or following the 'logic of care'). Given the complex interpersonal dynamics which underpin these phenomena, it is hardly surprising that quasi-experimental approaches to quality improvement (eg, feeding interpersonal skills scores back to practitioners ${ }^{35}$ or 'brief interventions' intended to improve patients' trust in doctors ${ }^{36}$ ) have had little impact.

Patient satisfaction scores and similar data may be collected and fed back to us whether we want to see them or not. Such metrics are likely to have greater impact when combined with a more humanistic and enduring model of professional development and quality improvement. 'Balint groups' have been running in the UK since the 1950s but their impact has yet to be evaluated using methods that most policymakers would find credible. Roberts et al have shown that it is possible to use critical consultation analysis in summative evaluation of both medical students and postgraduates. ${ }^{37} 38$ We recommend further research on how such in-depth analytic techniques could be used formatively, perhaps combined with the more widely used satisfaction or rate-your-relationship scales, ${ }^{1}$ in professional development.

Findings from both objective and subjective studies support the conclusion that a good therapeutic relationship is built over time through continuity of care and flourishes when encounters are not excessively time constrained. It follows that there are certain structural preconditions which will make such relationships more likely to occur (and conversely, that in the absence of these preconditions, good therapeutic relationships are unlikely to develop or be sustained). These preconditions include an organisational structure which allocates sufficient time to the consultation and which allows patients to ask for their preferred doctor or nurse by name. Evidence from discrete choice experiments suggests that patients are generally very willing to trade speed of access for an appointment with their 'usual' doctor. ${ }^{39}$ The use of personal lists in general practice greatly increases both continuity of care and patient satisfaction. ${ }^{40} 41$ All these structural preconditions can be readily measured and could be incentivised in some health systems.

In conclusion, a striking breadth of conceptual approaches, theoretical models and research designs have been brought to bear on the study of the therapeutic relationship. All illuminate 


\section{Box 1 Checklist for reflection-Are my therapeutic relationships as good as they could possibly be?}

1. Have I created the optimal structural preconditions for high-quality therapeutic relationships?

a. Do my consultations last 10 min or more?

b. Does my practice support patients in seeking continuity of care with a doctor/nurse of their choice (eg, by personal lists)?

c. How easy is it for patients to obtain an appointment with the doctor of their choice? (Note, however, that the more skilled the practitioner in establishing therapeutic relationships, the harder it may be to get an appointment)

2. How do my patients rate their relationship with me? For example,

a. Patient Perception of Physician Responsiveness

b. Doctors Interpersonal Skills Questionnaire

3. What do practice audits indicate, quantitatively and qualitatively, about my relationships with patients? For example,

a. How many significant event audits have involved relationship issues, and what were these?

b. How many complaints from patients have mentioned relationship issues, and what did they complain about?

4. When considering my consultations with patients (eg, in an analysis of videotaped consultations):

a. What proportion of the talk is socio-emotional ('care talk') as opposed to task focused ('cure talk')?

b. To what extent am I able to connect emotionally with my patients and show unconditional positive regard for them, thus allowing any 'hidden agenda' to surface and be dealt with?

c. To what extent can I manage the emotional aspects of the encounter without losing control or being personally overwhelmed?

d. To what extent do I acknowledge the patient's personhood and autonomy and accept 'the voice of the lifeworld' as legitimate in the clinical encounter?

e. To what extent am I able to use the spoken (and enacted) dialogue between myself and my patient as a tool in clinical management?

f. To what extent are my encounters with patients adaptive and sensitive to wider issues in their lives (such as consultations with other professionals, home and family context, carers' needs, etc)?

5. What efforts have I made in the last year to reflect on, and improve, the humanistic and relational aspects of my practice? For example,

a. Membership of Balint group?

b. Other group-based reflection opportunities?

c. Individual mentoring or supervision?

d. Peer observation of other practitioners?

6. If I consistently score poorly on the above, am I in the right job and/or do I need additional care or support myself?

this complex phenomenon in different ways and none provides a simple, unproblematic metric for assessing it. We caution against trying to resolve the differences between the different approaches, since they are philosophically incommensurable. There will always be a trade-off between not measuring this aspect of quality at all and distorting the picture by capturing only part of its essence.

It should be evident from this paper and its companion ${ }^{1}$ that there is no simple or technical way for practitioners to improve the quality of their relationships with patients. The evidence base reviewed in these papers offers academic insights into the nature of the therapeutic relationship but there is limited evidence of the efficacy of specific measures to improve this

\section{Summary points}

1. Scholars argue about whether and how the therapeutic relationship between practitioner and patient should be measured.

2. In this paper we review subjective approaches (oriented to producing interpretations rather than 'facts') and consider their philosophical assumptions, methodological approaches and key findings.

3. While no single metric or measure is capable of capturing all the dimensions and perspectives on the therapeutic relationship, different approaches illuminate this complex field in complementary ways. relationship. In box 1, we offer a preliminary 'checklist for reflection' which we hope will (a) help create the preconditions for strong therapeutic relationships, (b) help practitioners develop formative insights into their own relationships with patients and (c) prompt educators and policymakers to look beyond tick-box approaches to developing and incentivising quality in this area. There is much scope for further applied research, exploring and extending these preliminary suggestions with a view to building a quality improvement agenda around the therapeutic relationship.

Funding The King's Fund, 11-13 Cavendish Square, London, W1G OAN

Competing interests None declared.

Provenance and peer review Not commissioned; externally peer reviewed.

\section{REFERENCES}

1. Greenhalgh T, Heath I. Measuring quality in the therapeutic relationship. Part I: 'Hard' approaches (surveys and interaction assessment). Ouality and Safety in Health Care 2010:19:475-8.

2. Greenhalgh $\mathbf{T}$, Heath I. Measuring quality in the therapeutic relationship. London: Kings Fund, 2010

3. Greenhalgh T, Robert G, Macfarlane F, et al. Storylines of research in diffusion of innovation: a meta-narrative approach to systematic review. Soc Sci Med 2005:61:417-30.

4. Kuhn TS. The structure of scientific revolutions. Chicago: University of Chicago Press, 1962.

5. Greenhalgh T, Potts $\mathrm{H}$, Wong G, et al. Tensions and paradoxes in electronic patient record research: A systematic literature review using the meta-narrative method. Milbank 0 2009;87:729-88.

6. Lincoln YS. Emerging criteria for quality in qualitative and interpretive research. In Denzin N, Lincoln YS, eds. The qualitative inquiry reader. London: Sage, 2002

7. Balint M. The doctor, his patient and the illness. London: Routledge, 1956

8. Rogers C. Client-centered therapy: its practice, implications and theory. Philadelphia: Trans-Atlantic Publications, 1951. 
9. Charon R. Narrative medicine: form, function, and ethics. Ann Intern Med 2001; 134:83-7.

10. Frank A. Just listening: narrative and deep illness. Families, Systems and Health 1998:16:197-216.

11. Greenhalgh T, Robb N, Scambler G. Communicative and strategic action in interpreted consultations in primary health care: A Habermasian perspective. Soc Sci Med 2006;63:1170-87.

12. Robb N, Greenhalgh T. "You have to cover up the words of the doctor": the mediation of trust in interpreted consultations in primary care. $\mathrm{J}$ Health Organ Manag 2006;20:434-55.

13. Mol A. The logic of care: health and the problem of patient choice. London: Routledge, 2008

14. Freud S. The four fundamental concepts of psychoanlaysis. London: Penguin, 1973.

15. Horvath A0. The therapeutic relationship: from transference to alliance. J Clin Psychol 2000;56:163-73.

16. Blow AJ, Sprenkle DH, Davis SD. Is who delivers the treatment more important than the treatment itself? The role of the therapist in common factors. J Marital Fam Ther 2007;33:298-317.

17. Aristotle. Poetics. Translated by Malcolm Heath. London: Penguin, 1996.

18. Strauss AL. Chronic illness and the quality of life. St Louis: Mosby, 1975.

19. Bakhtin M. The dialogic imagination: four essays. Translated by Caryl Emerson and Michael Holquist. Austin: University of Texas Press, 1981.

20. Launer J. Narrative based primary care: a practical guide. Oxford: Radcliffe, 2002.

21. Buber M. Between man and man. London: Routledge, 1947.

22. Jodalen H, Vetlesen AJ. Closeness: an ethics. Oslo: Scandinavian University Press, 1997.

23. Nessa J. Autonomy and dialogue: about the doctor-patient relationship. In: Thomasma DC, Weisstub DN, Hervé C, eds. Personhood and health care. London: Kluwer Academic Publishers, 2001:355-62.

24. Mathews JJ. The communication process in clinical settings. Soc Sci Med 1983;17:1371-8.

25. Habermas J. The theory of communicative action. Boston: Beacon, 1987.

26. Scambler G, Britten N. System, lifeworld, and doctor-patient interaction. In: Scambler G, ed. Habermas critical theory and health. London: Routledge, 2001
27. Scambler G. Habermas, critical theory and health. London: Routledge, 2001.

28. Roberts C, Sarangi S. Theme-oriented discourse analysis of medical encounters. Med Educ 2005;39:632-40.

29. Mishler EG. The discourse of medicine: dialectics of medical interviews. Norwood NJ: Ablex, 1984.

30. Barry CA, Bradley CP, Britten N, et al. Patients' unvoiced agendas in general practice consultations: qualitative study. BMJ 2000;320:1246-50.

31. Barry CA, Stevenson FA, Britten N, et al. Giving voice to the lifeworld. More humane, more effective medical care? A qualitative study of doctor-patient communication in general practice. Soc Sci Med 2001;53:487-505.

32. Greener I. Patient choice in the NHS: the view from economic sociology. Social Theory and Health 2003;1:72-89.

33. Department of Health. Better information, better choices, better health: putting information at the centre of health. London: The Stationery Office, 2004.

34. Latour B. Reassembling the social: an introduction to actor-network-theory. Oxford: Oxford University Press, 1992.

35. Cheraghi-Sohi S, Bower P. Can the feedback of patient assessments, brief training or their combination, improve the interpersonal skills of primary care physicians? A systematic review. BMC Health Serv Res 2008;8:179.

36. McKinstry B, Ashcroft RE, Car J, et al. Interventions for improving patients' trust in doctors and groups of doctors. Cochrane Database Syst Rev 2006;(3): CD004134.

37. Roberts C, Wass V, Jones R, et al. A discourse analysis study of 'good' and 'poor' communication in an OSCE: a proposed new framework for teaching students. Med Educ 2003;37:192-201.

38. Roberts C, Sarangi S, Southgate L, et al. Oral examinations-equal opportunities, ethnicity, and fairness in the MRCGP. BMJ 2000;320:370-5.

39. Gerard K, Salisbury C, Street D, et al. Is fast access to general practice all that should matter? A discrete choice experiment of patients' preferences. J Health Serv Res Policy 2008;13(Suppl 2):3-10.

40. Roland M, Mayor V, Morris R. Factors associated with achieving continuity of care in general practice. J $R$ Coll Gen Pract 1986;36:102-4.

41. Baker R, Streatfield J. What kind of general practice do patients prefer? Exploration of practice characteristics associated with patient satisfaction. Br J Gen Pract 1995; 45:693-710. 